\title{
Exilio y nostalgia. Dibujos inéditos y libros ilustrados de Picasso en la colección de la familia Arias
}

\author{
Sala de exposiciones Fundación Picasso \\ Del 24 de octubre al 10 de febrero de 2020
}

En Exilio y nostalgia, se exponen una serie de dibujos que hasta ahora habían permanecido totalmente inéditos. Ahí, en la posibilidad de contemplar por vez primera este conjunto de obras, reside sin duda el gran interés que merecidamente ha despertado esta muestra entre el público y la razón de los numerosos ecos que de ella se han hecho los medios de comunicación generalistas.

La colección objeto de la muestra se compone de 187 piezas: 103 dibujos, 4 libros ilustrados con 77 estampas originales y 7 dedicatorias firmadas, que la familia de Eugenio Arias cedió al Museo-Casa Natal en 2017, a través de un depósito a cinco años, por lo que, por lo pronto -en espera de los esfuerzos del ayuntamiento de la ciudad por conservarla durante más tiempo o tal vez por hacerse con ella de manera definitiva-, permanecerán en Málaga hasta 2022.

Las piezas del legado Arias vienen a sumarse a la gran colección de obra gráfica y libros ilustrados que ya atesora la Casa Natal. Y esta exposición se suma, de forma sobresaliente, a los numerosos eventos culturales que la institución, muy activa, organiza a lo largo de todo el año, y muy especialmente en torno a las celebraciones del "octubre picassiano».

El montaje, dada la disposición en tres estancias de la sala, se corresponde con una concepción tripartita, de manera que el bloque central actúa a manera de núcleo sobre el que orbitan los otros dos, o como sanctasanctórum del templo.

Siguiendo el orden de la visita, en el primer bloque se exhibe el volumen de Escritos y dibujos publicado en 1961 por Camilo José Cela para las ediciones de la mallorquina Papeles de Son Armadans. Se trata de un ejemplar en el que la mano del pintor interviene sobre las reproducciones litográficas y sobre los textos impresos, de modo que el libro pasa de ser uno más -eso sí, dentro una pequeña tirada de lujo- a convertirse en un objeto único, un regalo exclusivo para Eugenio Arias con motivo de su quincuagésimo séptimo cumpleaños. Por medio de rotuladores de colores tanto para el papel del interior como para la cubierta y con- tracubierta de tela, Picasso realiza una serie de dibujos que van desde el arabesco decorativo, el tirabuzón o la caligrafía simulada, hasta las figuras humanas, pasando por un conjunto de trazos y signos -sol, estrella, espiral-. Alguna de estas intervenciones recuerda claramente a las constelaciones musicales con las que Picasso ilustró para Ambroise Vollard La obra maestra desconocida de Honoré de Balzac, en los años treinta, siendo de lo más abstracto que puede hallarse en toda su producción.

En las tres reproducciones litográficas de desnudos que contiene el libro, a través de la añadidura de curvas y contracurvas de diferente color, que puede entenderse como un juego de luces y sombras, de claroscuro, se consigue dotar de profundidad a las escenas. En una de ellas -no expuesta en las paredes de la sala-, la adición de dos cabezas de ancianos, en lasciva actitud de mirones, asomados a la ventana, provoca que el interior con desnudos se convierta en una clara alusión al tema bíblico de Susana y los viejos.

Pero de esta serie destaca, sin lugar a dudas, el más elaborado de los dibujos: el rostro de hombre barbudo [1] que Picasso incluye en la portadilla de Dibujos, realizado con rotuladores de seis colores, de gran belleza y de no poca complejidad técnica. Carlos Ferrer Barrera, comisario de esta exposición, se ha encargado de señalar la presencia de esta figura como uno de los múltiples leitmotivs a lo largo de la obra picassiana, relacionándola con el padre, como imagen arquetípica del varón en la tradición plástica mediterránea y, a un tiempo, como alter ego del propio pintor, aunque su apariencia esté muy alejada del físico real del artista malagueño. En todo caso, parece claro el guiño al barbero Arias, no solo por representar Picasso aquí a un hombre barbudo, sino también porque los mismos trazos del dibujo recuerdan a una maraña de pelos rizados, como los que pueden quedar en el suelo de la peluquería una vez despachado un cliente.

El segundo bloque, que es, como hemos dicho, la sección central de la muestra, se compone de 63 páginas del periódico $A b c-4$ de ellas dobles- en las que, con gran es- 
pontaneidad, a rotulador, cera o lápices de colores, Picasso retrata toros, toreros y picadores e improvisa escenas de la lidia, o se limita a señalarle a Arias cierta crónica taurina que parece interesarle especialmente, por medio de un marco, de un resalte o de algunas palabras. En una elección que no parece casual, algunos de estos dibujos están realizados con los tres colores de la bandera republicana española.

Entre la complicidad con el amigo y la humorada, por medio de un trazo rápido y esquemático, Picasso logra plasmar escenas cómicas, como las de algunos toreros huyendo despavoridos del astado. Asimismo, aprovechando el blanco de fondo, es capaz de representar el escorzo de un toro que vuelve la cabeza. $\mathrm{O}$, con una sola línea, el perfil conseguido del animal [2]. O, con unas pocas manchas, el gesto de espera de un matador o los garbosos andares de otro durante el paseíllo.

En una de las páginas, aparecen tres cucarachas, cuyas antenas el profesor Eugenio Carmona se ha encargado de relacionar oportunamente con las astas del toro. Además, como ha señalado el comisario de la exposición, en la página trasera a esta hay un anuncio de pintura industrial con poder insecticida -y el texto comercial hace expresa mención de este animal-, por lo que estamos de nuevo ante la ironía autorreferencial: si el pintor de brocha gorda se dedica a eliminar estos desagradables bichos, Picasso los trae al papel.

En otra de ellas, Picasso se muestra sorprendido al ver reproducida una de sus aguatintas de la Tauromaquia de Pepe Illo en las páginas del Abc, diario afín al régimen, y la califica burlonamente de «inserción espontánea», comparándola con el salto al ruedo de un espontáneo.

El tercer y último bloque, es, a pesar de su indiscutible valor, la sección de menor interés de las tres que componen la muestra, por el simple hecho de que estas obras ya han sido exhibidas en otras ocasiones y no aportan la novedad de las otras dos. No obstante, completan el recorrido por la amistad entre Picasso y Arias y forman parte importante del legado de este último.

Aquí podemos ver algunos ejemplares de libros ilustrados de Picasso dedicados a Arias, como una de las 30 pruebas de artista de Songe et mensonge de Franco (Sueño y mentira de Franco), de 1937, cuya edición fue sufragada por el propio Picasso y cuyos beneficios se destinaron en favor de la causa republicana; La Tauromaquia o arte de torear de

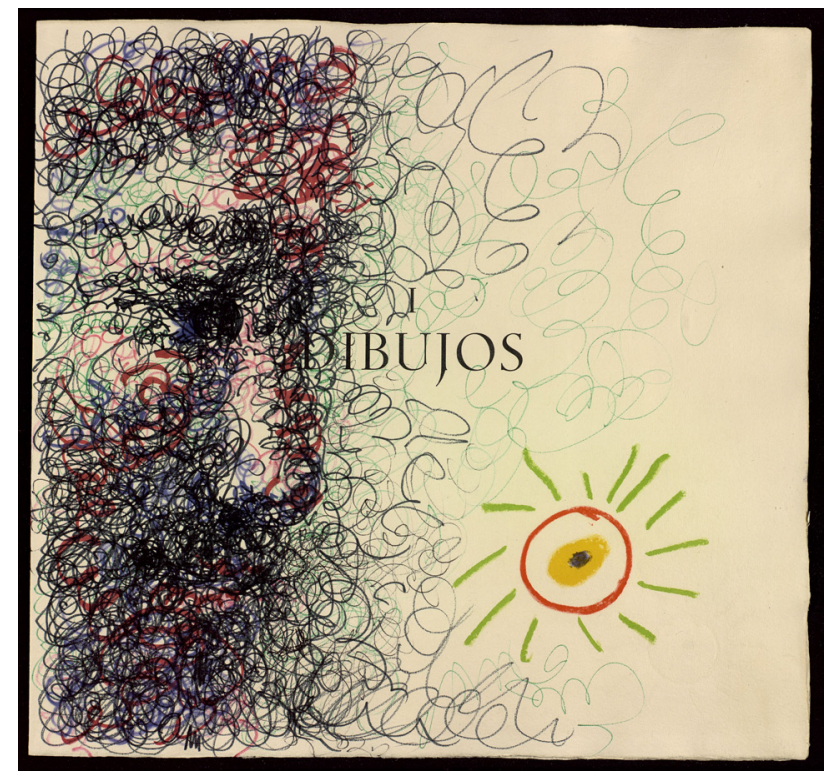

1. Pablo Ruiz Picasso, Rostro de hombre barbudo, 1966. Colección Familia Arias

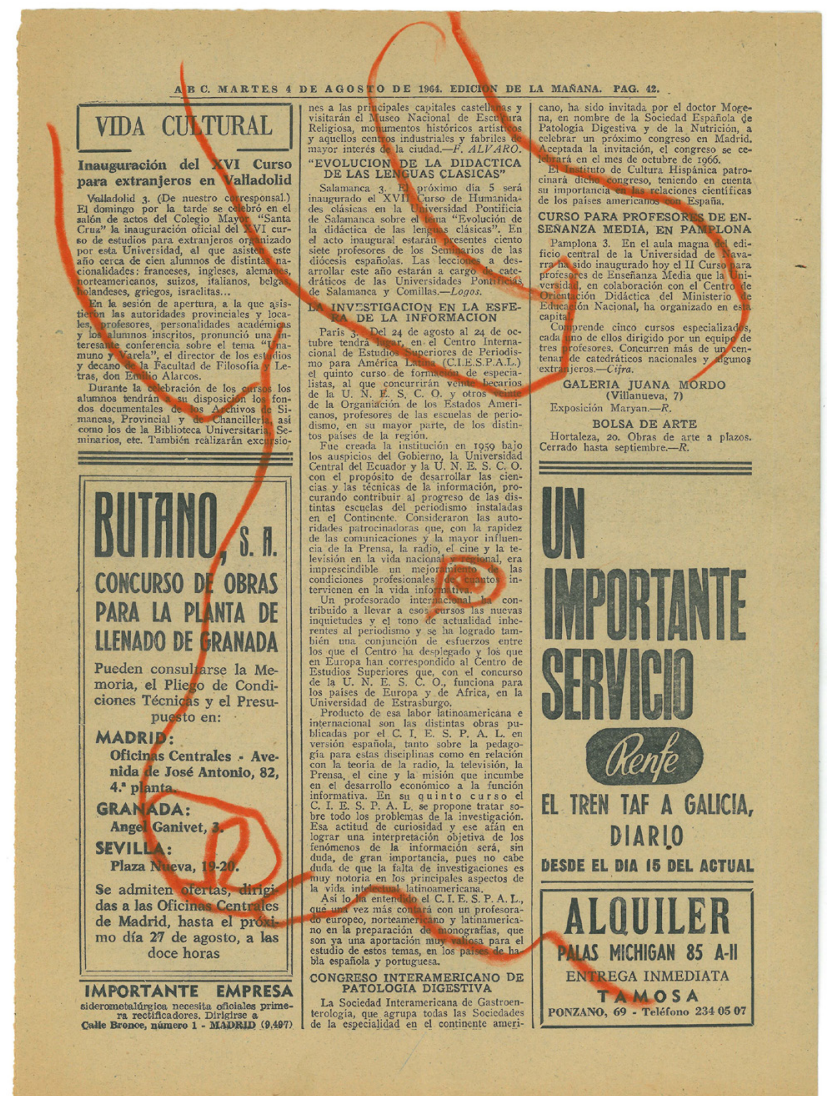

2. Pablo Ruiz Picasso, Gran cabeza de toro, 1964. Colección Familia Arias 


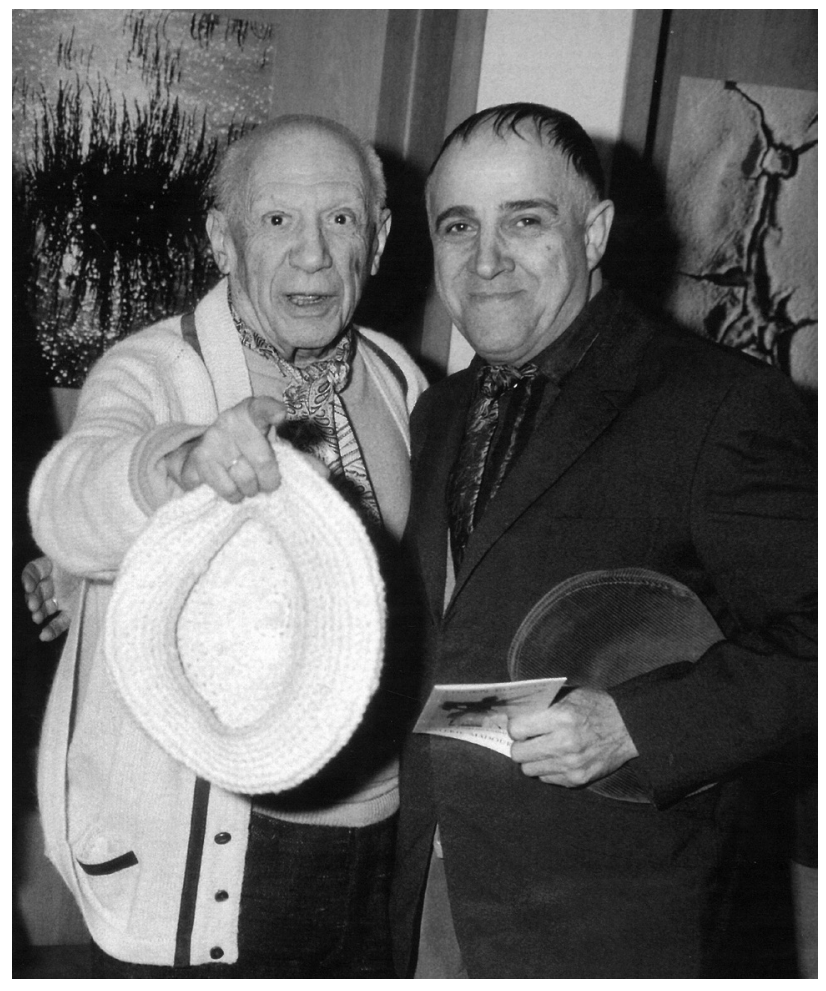

3. Picasso y Arias en la inauguración de una exposición de fotografías de Lucien Clergue (foto: Henri Traverso)

José Delgado (alias Pepe Illo), de 1959, o la edición de Carmen, de Prosper Mérimée (1949). En el pasillo intermedio se muestran las ilustraciones de la edición póstuma (1966) del poema Sable mouvant, de Pierre Reverdy.

Por último, repartidas entre el pasillo intermedio y la tercera estancia, encontramos otra serie de dedicatorias, como la del número especial del periódico Le patriote que, con fecha de 25 de octubre de 1961, homenajea a Picasso por su octogésimo cumpleaños -en la que Arias es llamado «mi amigo y mi hijo»-; o la que va acompañada por un «autorretrato burlesco", en el que, a partir de una fotografía de perfil, Picasso se trasviste de saltimbanqui, o aquella de El entierro del conde de Orgaz (1970), en la que el Picasso escritor se autodenomina curiosamente «el autor».

Además, las paredes de la sala han sido cubiertas con algunas fotografías [3] que dan muestra de la profunda amistad y de la relación paterno-filial que unió a ambos españoles en su exilio en el Mediodía francés. De hecho, este es uno de los principales discursos de la exposición, la reivindicación de la importancia que tuvo el injustamente llamado «barbero de Picasso» en la vida del artista. A ambos les unía su condición de expatriados, su afición a la tauromaquia y su compromiso político. Arias fue mucho más que un simple fígaro para Picasso. Prueba más que suficiente de ello es por ejemplo el hecho de que fuera padrino de su boda con Jacqueline, honor que solo les había correspondido antes a los poetas Guillaume Apollinaire y Paul Eluard. O que fuese también el encargado de llevar a cabo un gesto tan simbólico -y tan íntimo- como el de ponerle la capa española en su lecho de muerte, a petición de Jacqueline.

La exposición ha venido acompañada de un estupendo catálogo con una semblanza de esta amistad por parte de Madeleine Arias, nuera de Eugenio Arias, y cuyos textos críticos han corrido a cargo de especialistas como Eugenio Carmona y Pablo Rodríguez, Androula Michaël, Claustre Rafart Planas, Alicia Navarro y el propio comisario, Carlos Ferrer. El catálogo se cierra con dos trabajos de Rafael Inglada: una entrevista a Arias efectuada en 1990 y una minuciosa cronología que abarca más de veinte años de amistad.

Álvaro Galán Castro Universidad de Málaga 